EDITORIAL

\title{
End-of-life Care in the Intensive Care Unit: Better Late Than Never?
}

Jigeeshu V Divatia

Indian Journal of Critical Care Medicine (2020): 10.5005/jp-journals-10071-23496

Over the past two decades, intensive care medicine in India has made tremendous progress. Several intensive care units (ICUs) have the capability to offer mechanical ventilation, hemodynamic management, renal replacement therapy, as well as advanced, cutting-edge technology, including mechanical and extracorporeal renal, respiratory, hepatic, and cardiac support. These interventions have the potential to replace or assist vital organ functions and prolong life for several days, weeks, and even months, in patients who may have little or no chance of survival without such support, or of returning to a reasonable quality of life. Prolonged intensive care may merely delay death and result in pain and suffering without any potential benefit to the patient. In addition, it would cause significant emotional, social, and financial distress in the patient's family. When the dying process has set in, and death is imminent, a technologically prolonged dying process takes away the serenity and dignity of death, and nature should be allowed to take its own course. At this stage, the focus of care should shift from aggressive life-sustaining interventions to end-of-life care (EOLC).

End-of-life care is an approach to a terminally ill patient that shifts the focus of care to symptom control, comfort, dignity, quality of life, and quality of dying rather than treatments aimed at cure or prolongation of life. ${ }^{1}$ End-of-life care in the ICU is inextricably linked to withholding cardiopulmonary resuscitation (CPR) or do not resuscitate (DNR), withholding life support (WHLS), and withdrawal of life support (WDLS), all performed after discussion with and agreement between the treating medical team and the patient's family. Unfortunately, these interventions are often lumped together under the term euthanasia, especially in the press and electronic media. Any discussion on the issues surrounding EOLC tends to be emotive, often generating more heat than light. The Supreme Court (SC) of India has added to the confusion by coining the term "passive euthanasia" for WHLS and WDLS, and "active euthanasia" for the killing of the individual by direct active medical intervention. ${ }^{2}$ This terminology is misleading and unhelpful. It is essential to have clear definitions about the various terms and definitions used in this context. The Indian Council of Medical Research (ICMR) has produced an excellent document clarifying the terminology used in limitation of treatment and providing palliative care at end of life. ${ }^{3}$

Terminal illness is an irreversible or incurable disease condition from which death is expected in the foreseeable future. "Do not resuscitate" avoids futile CPR when the patient has no signs of life and maintains the dignity of the patient. The ICMR recognizes DNR as a valid medical decision where, in the best judgment of the treating physician, CPR would be inappropriate, nonbeneficial, and likely to prolong the suffering of the patient. ${ }^{4}$ In the ICU setting, WHLS and WDLS are performed in a terminally ill patient where death will occur if the vital organ support is not provided. Thus, WHLS or WDLS would lead to the natural death of the patient.
Department of Anesthesia, Critical Care and Pain, Tata Memorial Hospital, Homi Bhabha National Institute, Mumbai, Maharashtra, India Corresponding Author: Jigeeshu V Divatia, Department of Anesthesia, Critical Care and Pain, Tata Memorial Hospital, Homi Bhabha National Institute, Mumbai, Maharashtra, India, Phone: +91 9869077435, e-mail: jdivatia@yahoo.com

How to cite this article: Divatia JV. End-of-life Care in the Intensive Care Unit: Better Late Than Never? Indian J Crit Care Med 2020;24(6): 375-377.

Source of support: Nil

Conflict of interest: None

When the dying process has not set in, patients who may have a terminal or incurable disease but do not require life-supporting treatments would require euthanasia, an active intervention (e.g., a lethal injection), to bring about death. Thus, the essence of WHLS or WDLS is not just the passive nature of the intervention; it is the timing in relation to the onset of the natural dying process and the need for artificial organ support.

The crucial recognition that WHLS and WDLS are performed when the death is inevitable without life support, and that institution of such life support is of no benefit to the patient helps remove any moral or ethical objections to WHLS and WDLS; in fact, it makes WHLS and WDLS the most appropriate course of action. The Indian Society of Critical Care Medicine (ISCCM) has consistently advocated ethical and transparent decision-making, EOLC, and palliative care in Indian ICUs. ${ }^{5-7}$ The ISCCM recognizes DNR, WHLS, and WDLS as ethical interventions, but not euthanasia and physician-assisted suicide. Indian intensivists appear to be in favor of EOLC practices when aggressive care is potentially inappropriate. In an international study, 176 physicians from 51 ICUs from India responded to a selfadministered structured and scenario-based survey conducted among 1,465 physicians at 466 ICUs in 16 Asian countries and regions. ${ }^{8}$ For patients with no chance of recovering a meaningful life, $75 \%$ Indian intensivists almost always or often withheld, and $30 \%$ withdrew life-sustaining treatment, and $80 \%$ felt that withholding and withdrawal of life-sustaining treatments were ethically not the same. In a hypothetical scenario of a patient with hypoxic-ischemic encephalopathy, who suffered a recurrent cardiac arrest, 77\% strongly agreed that mechanical ventilation could be withheld or withdrawn as part of limitation of life-sustaining therapy in EOLC, and $90 \%$ would implement written or verbal DNR orders. Only $36 \%$ would maintain mechanical ventilation and start antibiotics and vasopressors if the patient with hypoxic-ischemic encephalopathy developed pneumonia with septic shock. Financial considerations may play a part in decision-making. In another scenario, if the family of a patient with a reasonably good chance of recovery insisted that 
life-sustaining treatments be withdrawn to avoid further medical bills, 7.4\% Indian intensivists would withhold or withdraw treatment. ${ }^{9}$

Despite this seemingly overwhelming opinion in favor of EOLC (perhaps in a select group of intensivists who responded to the questionnaire), there are social, cultural, religious, and economic barriers to EOLC in Indian ICUs, on the part intensivists, primary physicians, as well as patients and their families. Fear of legal implications of WHLS and WDLS appears to play an important part. ${ }^{10}$ In the last decade, there have been landmark decisions from the SC pertinent to EOLC. ${ }^{11}$ In the Aruna Shanbaug case, the SC ruled that "passive euthanasia" was permissible, but required prior approval from the high court. ${ }^{2}$ In the Common Cause case, ${ }^{12}$ a five-judge constitution bench ruled that the right to life with dignity includes the smoothening of the process of dying when the person is in a vegetative state or is living exclusively by the administration of artificial aid that prolongs the life by arresting the dignified and inevitable process of dying. Importantly, this right was brought within the ambit of Article 21 of the Constitution, which guarantees the right to life and liberty as a fundamental right. The $\mathrm{SC}$ bench also allowed Advance Directives or living wills. However, an elaborate and tedious procedure was prescribed, which makes implementation of a living will or WHLS/WDLS practically impossible for critically ill patients. Thus, in both landmark cases, 2,12 the SC took two steps forward but three steps back; WHLS/WDLS was considered lawful, but the procedures prescribed to safeguard the interests of patients and society are impractical and difficult to follow.

The application of EOLC in general, and WHLS and WDLS in particular, has a patchy record in Indian ICUs. A review article on EOLC in 2003 included unpublished data from an ICU of a tertiary hospital in Northern India. ${ }^{13}$ Life support was limited in only $22 \%$ of 238 deaths (48 patients). In 38 out 48 patients (79\%), limitation of treatment was in the form of left against medical advice (LAMA). The Indian Intensive Care Case Mix and Practice Patterns Study (INDICAPS) was a point prevalence study that included data of 4,038 adult patients from 120 Indian ICUs between 2010 and 2011. ${ }^{14}$ There were 546 deaths and 183 terminal discharges (TDs) from ICU (including LAMA). All TDs were considered as nonsurvivors, resulting in an ICU mortality of $729 / 4038$ (18.1\%). Of the 729 nonsurvivors, 276 (38\%) had some limitation of treatment. A total of 183 (25\%) were TDs, 35 (4.8\%) had DNR, 45 (6.2\%) had WHLS, and $13(1.8 \%)$ had WDLS. Two-thirds of all treatment limitations were TDs including LAMA. Thus, LAMA was widely practiced. Self-paying patients and treatment in private hospitals ICUs were independently associated with limitation of life-sustaining treatment, suggesting that financial considerations may have played a role..$^{15}$

Left against medical advice is seen to absolve the doctor and hospital of all responsibility for the consequences of withdrawing treatment and is considered the best solution in an ambiguous legal environment. It is often done in the setting of futility and in the setting of inability to pay, and with the tacit encouragement of doctors and hospital administrators. However, it is not different from WDLS done in a hospital with the consent of the family. More importantly, LAMA violates the principles of autonomy (potentially coercive in the setting of inability to pay for treatment), beneficence, and nonmalfeasance (no provision of pain management, sedation or palliative care, abandonment of the patient, and abdication of responsibility by the doctor).

In two other reports from selected ICUs, EOLC was practiced in $34-49 \%$ of deaths in the ICU, with WHLS (including DNR) being the most common (92-93\% of all EOLC decisions). ${ }^{16,17}$ The WDLS was uncommon (7-8\%). No patient was terminally discharged LAMA. These data again suggest that even in these ICUs, with interest and expertise in EOLC, WHLS was the preferred mode of treatment limitation, and that WDLS was uncommon.

End-of-life care should not be restricted to the ICU. Patients with terminal illness who will not benefit from escalation of care should not be admitted to the ICU; EOLC including palliative care can be given in the hospital ward. In a retrospectively study of 122 patients who died after admission to a medical unit of a tertiary care hospital in southern India, ${ }^{18}$ only 48 patients (39\%) were referred to the ICU. End-of-life care decisions were taken in 81 patients (66.4\%) patients; of these WHLS was done in $76.5 \%$ and WDLS in $23.5 \%$ patients. All decisions were taken after a detailed discussion by the treating team with the nearest relatives of the patient about the prognosis and obtaining consent.

The study by Choudhuri et al. in this issue of the Indian Journal of Critical Care Medicine adds to the scanty literature on EOLC in Indian ICUs. ${ }^{19}$ Choudhuri et al. report the results of a retrospective study conducted to investigate the factors responsible for delay in the initiation of EOLC after recognition of treatment futility in their seven-bed ICU over a period of 5 years (2014-2018). These data shed some light on factors that are associated with delays in initiation of EOLC, even after futility has been recognized. There are several remarkable features in their EOLC practice. Treatment futility was decided jointly between the primary physician and the intensivist and recorded in the notes. No patient left the hospital against medical advice (LAMA), and WHLS was done in all patients who received EOLC; WDLS was not practiced. Family counseling was done after the EOLC process and family satisfaction was noted in the patient record. Of the 107 terminally ill patients in whom treatment was considered futile, $60 \%$ underwent early initiation of EOLC (within 48 hours of determination futility), while $40 \%$ had delayed initiation ( $>48$ hours after determination of futility). The mean time to initiation was significantly longer with late initiation compared to early initiation ( $5.1 \pm 1.6$ days vs $1.3 \pm 0.4$ days, $p=0.01$ ). The major reasons for delayed initiation of EOLC were prognostic dilemma (30.2\%), reluctance of the family members to accept EOLC care $(44.1 \%)$, ambivalence of the primary physician to start EOLC care (18.6\%), and hesitancy of the intensivist to start EOLC (6.9\%). The authors suggest that better counseling and communication with family members may reduce the delay in initiating EOLC. However, it is not unreasonable for families to be hesitant to make a decision at the first suggestion of EOLC. Hesitancy on the part of doctors involved in initiating EOLC occurred on over $25 \%$ instances. The authors suggest that physicians are reluctant to discuss EOL till the exhaustion of all possible options, and are hesitant to discuss EOLC with family members. These problems have been identified and discussed at length, ${ }^{20}$ with no easy solution in sight. Perhaps a greater orientation toward patient communication and palliative care during undergraduate and postgraduate medical education and recognition of the limits of medical treatment care may help.

Finally, EOLC will improve only when doctors recognize it as a genuine method of caring for terminally ill patients, and not as a last recourse when ICU care is financially unviable. End-of-life care cannot improve as long as doctors do not realize that LAMA does not meet the ethical standards of beneficence and nonmalfeasance. While we yearn for a law permitting WHLS/WDLS that is both explicit and practical, we must do what is medically and ethically correct. We cannot continue to inflict pain and suffering on patients by offering treatments that have no benefit, and deny them a peaceful, natural death. 


\section{References}

1. Indian Council of Medical Research 2018. Definition of terms used in limitation of treatment and providing palliative care at end of life. Available at https://main.icmr.nic.in/sites/default/files/Books/ Definition_of_terms_used_in_limitation_of_treatment_and_ providing_palliative_care_at_end_of_life.pdf. Accessed July 6, 2020.

2. Aruna Ramachandra Shanbaug vs. the Union of India \& Ors. WRIT Petition (CRIMINAL) No. 115 OF 2009 (Supreme Court of India Proceedings); 2009.

3. Salins N, Gursahani R, Mathur R, lyer S, Macaden S, Simha N, et al. Definition of terms used in limitation of treatment and providing palliative care at the end of life: the indian council of medical research commission report. Indian J Crit Care Med 2018;22(4):249-262. DOI: 10.4103/ijccm.IJCCM_165_18.

4. Mathur R. ICMR consensus guidelines on 'do not attempt resuscitation'. Indian J Med Res 2020;151(4):303-310. DOI: 10.4103/ ijmr.IJMR_395_20.

5. Mani RK, Divatia JV, Chawla R, Kapadia F, Myatra SN, Rajagopalan R, et al. Limiting life-prolonging interventions and providing palliative care towards the end-of-life in indian intensive care units. Indian J Crit Care Med 2005(2):96-107. DOI: 10.4103/0972-5229.17097.

6. Mani RK, Chawla R, Kapadia F, Rajagopalan R, Amin P, Khilnani P, et al. Guidelines for end-of-life and palliative care in Indian intensive care units' ISCCM consensus ethical position statement. Indian J Crit Care Med 2012;16(3):166-181. DOI: 10.4103/0972-5229.102112.

7. Myatra SN, Salins N, lyer S, Macaden SC, Divatia JV, Muckaden M, et al. End-of-life care policy: an integrated care plan for the dying: a joint position statement of the Indian society of critical care medicine (ISCCM) and the Indian association of palliative care (IAPC). Indian J Crit Care Med 2014;18(9):615-635. DOI: 10.4103/0972-5229.140155.

8. Phua J, Joynt GM, Nishimura M, Deng Y, Myatra SN, Chan YH, et al. Withholding and withdrawal of life-sustaining treatments in intensive care units in Asia. JAMA Intern Med 2015;175(3):363-371. DOI: 10.1001/ jamainternmed.2014.7386.

9. Phua J, Joynt GM, Nishimura M, Deng Y, Myatra SN, Chan YH, et al. Withholding and withdrawal of life-sustaining treatments in lowmiddle-income versus high-income Asian countries and regions.
Intensive Care Med 2016;42(7):1118-1127. DOI: 10.1007/s00134-0164347-y.

10. Barnett VT, Aurora VK. Physician beliefs and practice regarding endof-life care in india. Indian J Crit Care Med 2008;12(3):109-115. DOI: 10.4103/0972-5229.43679.

11. Mani RK, Simha SN, Gursahani R. The advance directives and foregoing of life support: where do we stand now? Indian J Crit Care Med 2018;22(3):135-137. DOI: 10.4103/ijccm.IJCCM_116_18.

12. Common Cause (A Regd. Society) vs Union Of India on 9 March, 2018. Available at https://indiankanoon.org/doc/184449972/. Accessed July 06, 2020.

13. Mani RK. Limitation of life support in the ICU: ethical issues relating to end of life care. IJCCM 2003;7(2):112-117.

14. Divatia JV, Amin PR, Ramakrishnan N, Kapadia FN, Todi S, Sahu S, et al. Intensive care in India: the Indian intensive care case mix and practice patterns study. Indian J Crit Care Med 2016;20(4):216-225. DOI: $10.4103 / 0972-5229.180042$.

15. Divatia JV, Kapadia FN. INDICAPS study investigators. limitation of life-sustaining treatments in indian ICUs: data from the Indian intensive care case mix and practice patterns study (INDICAPS study). Intensive Care Med Exp 2017;5(Suppl 2):484-485. , 44.

16. Kapadia F, Singh M, Divatia J, Vaidyanathan P, Udwadia FE, Raisinghaney $\mathrm{SJ}$, et al. Limitation and withdrawal of intensive therapy at the end of life: practices in intensive care units in Mumbai, India. Crit Care Med 2005;33(6):1272-1275. DOI: 10.1097/01. ccm.0000165557.02879.29.

17. Mani RK, Mandal AK, Bal S, Javeri Y, Kumar R, Nama DK, et al. Endof-life decisions in an Indian intensive care unit. Intensive Care Med 2009;35(10):1713-1719. DOI: 10.1007/s00134-009-1561-x.

18. Kuriakose CK, Chandiraseharan VK, John AO, Bal D, Jeyaseelan $V$, Sudarsanam TD. End-of-life decisions: a retrospective study in a tertiary care teaching hospital in India. Indian J Med Res 2019;150(6):598-605. DOI: 10.4103/ijmr.IJMR_1409_17.

19. Choudhuri AH, Sharma A, Uppal R. Effects of delayed initiation of end-of-life (EOL) care in terminally ill intensive care unit (ICU) patients. Ind J Crit Care Med 2020;24(6):404-408.

20. Mani RK. End-of-life care in India. Intensive Care Med 2006;32(7): 1066-1068. DOI: 10.1007/s00134-006-0185-7. 